\title{
Plugging Braking of Two-PMSM Drive in Subway Applications with Fault-Tolerant Operation
} \author{
College of Electrical and Electronic Technology \\ Middle Technical University \\ adelrazan@gmail.com
}

Adel A. obed Ali K. Abdulabbas

Department of Electrical Power Engineering Department of Electrical Engineering

\author{
College of Engineering \\ Basra University \\ ali_univbasra75@yahoo.com
}

\author{
Ahmed J. Chasib \\ Department of Electrical Engineering \\ College of Engineering \\ Basra University \\ alahmeda15@yahoo.com
}

\begin{abstract}
The Permanent Magnet Synchronous Motor (PMSM) is commonly used as traction motors in the electric traction applications such as in subway train. The subway train is better transport vehicle due to its advantages of security, economic, health and friendly with nature. Braking is defined as removal of the kinetic energy stored in moving parts of machine. The plugging braking is the best braking offered and has the shortest time to stop. The subway train is a heavy machine and has a very high moment of inertia requiring a high braking torque to stop. The plugging braking is an effective method to provide a fast stop to the train. In this paper plugging braking system of the PMSM used in the subway train in normal and fault-tolerant operation is made. The model of the PMSM, three-phase Voltage Source Inverter (VSI) controlled using Space Vector Pulse Width Modulation technique (SVPWM), Field Oriented Control method (FOC) for independent control of two identical PMSMs and fault-tolerant operation is presented. Simulink model of the plugging braking system of PMSM in normal and fault tolerant operation is proposed using Matlab/Simulink software. Simulation results for different cases are given.
\end{abstract}

Keywords: PMSM, VSI, SVPWM, FOC, Fault tolerant operation, plugging braking.

\section{Introduction}

Due to the high efficiency, high torque density and good power factor, the PMSMs are used in many industrial applications and in highperformance drive application such as submarine propulsion, home applications, wind generation systems, electric vehicle, subway transportations, etc. [1-3].

The subway train is moving below the surface of earth. One of the significant solutions can be used to solve the traffic problem is the uses of the subway train. The loss in time that many people suffer from it in traffics and the bad effect on environment caused by the vehicle working on diesel can be ended by using the subway trains. Subway systems are cheaper, safer, and more economic than other transport systems.

In the instant that the three-phase power supply is disconnected from motor, the motor will stop due to the braking effects of the mechanical load, but there are types of mechanical load has a large amount of the kinetic energy with speed such as the subway train. In this case the train will naturally continue to moving at high speed for long time especially when there is little friction present in the system. Therefore, the braking system necessary is necessary used to stop the motor.

There are two main techniques which are used for electrical motors braking; the friction braking and the electrical braking. The friction braking system applies a friction force on the moving parts for stopping. The electrical braking techniques can be classified in to three types; regenerative, dynamic and plugging braking [4].

The regenerative braking converts the kinetic energy of the rotor to electrical power and send it back to the power source, while in the dynamic braking the regenerated energy is dissipated in the internal/external resistance as heat energy. Due to the advantages of plugging braking, simplicity and its need to short time for its effective, it is selected here.

In this paper the plugging braking is proposed for a subway train, two identical 
PMSM's are used to drive train car. Each motor has independent control using FOC to drive a voltage source inverter using the SVPWM technique. The use of plugging braking is implemented in Simulink for normal operation and fault tolerant operation in which the two VSI's are reconfigured to a single VSI with five legs. A nonadjacent strategy is used to prevent from the over current in the common leg. A simulation result for normal operation with braking and fault tolerant operation with braking are given. One or two motor can be used for braking with rated torque and different reference speed are also proposed and implemented.

\section{FOC of PMSM Drives by SVPWM Voltage Source Inverter}

\section{A. PMSM Mathematical Model}

The PMSM consist of 3-phase stator windings and rotor with permanent magnets. The stator windings are distributed over pole pairs, with phase axis spaced by $2 \pi / 3$ electrical radians. The PMSM mathematical model in rotor reference frame is illustrated in the following equations [5-7].

$\frac{\mathrm{di}_{\mathrm{d}}}{\mathrm{dt}}=-\frac{\mathrm{R}_{\mathrm{s}}}{\mathrm{L}_{\mathrm{d}}} \mathrm{i}_{\mathrm{d}}+\frac{\mathrm{L}_{\mathrm{q}}}{\mathrm{L}_{\mathrm{d}}} \omega_{\mathrm{r}} \mathrm{i}_{\mathrm{q}}+\frac{1}{\mathrm{~L}_{\mathrm{d}}} \mathrm{v}_{\mathrm{d}}$

$\frac{\mathrm{di}_{\mathrm{q}}}{\mathrm{dt}}=-\frac{\mathrm{R}_{\mathrm{s}}}{\mathrm{L}_{\mathrm{q}}} \mathrm{i}_{\mathrm{q}}-\frac{\mathrm{L}_{\mathrm{d}}}{\mathrm{L}_{\mathrm{q}}} \omega_{\mathrm{r}} \mathrm{i}_{\mathrm{d}}-\frac{1}{\mathrm{~L}_{\mathrm{q}}} \omega_{\mathrm{r}} \psi_{\mathrm{f}}+\frac{1}{\mathrm{~L}_{\mathrm{q}}} \mathrm{v}_{\mathrm{q}}$

$\mathrm{T}_{\mathrm{em}}=\frac{3}{2} \frac{\mathrm{p}}{2}\left(\psi_{\mathrm{d}} \mathrm{i}_{\mathrm{q}}-\psi_{\mathrm{q}} \mathrm{i}_{\mathrm{d}}\right)$

$\frac{\mathrm{d} \omega_{\mathrm{r}}}{\mathrm{dt}}=\frac{1}{\mathrm{~J}}\left(\mathrm{~T}_{\mathrm{em}}-\mathrm{T}_{\text {mech }}-\mathrm{T}_{\mathrm{damp}}\right)$

Where $R_{s}$ is stator resistance per phase, $L_{d}$, $\mathrm{L}_{\mathrm{q}}$ are the $\mathrm{dq}$ inductances, $\omega_{\mathrm{r}}$ is rotor angular velocity, $\Psi_{\mathrm{f}}$ is the permanent magnet flux, $i_{d}, i_{q}$, $\mathrm{v}_{\mathrm{d}}, \mathrm{v}_{\mathrm{q}}$ are stator currents and voltages in dq axis, $\psi_{\mathrm{d}}, \psi_{\mathrm{q}}$ are flux linkage when referring to $\mathrm{d}$ and $\mathrm{q}$ axis, $\mathrm{T}_{\mathrm{em}}$ is electromagnetic torque, $\mathrm{T}_{\text {damp }}$ is fractional torque, $\mathrm{T}_{\mathrm{L}}$ is load torque; and $\mathrm{J}$ is the rotor inertia.

\section{B. Three Phase VSI Based SVPWM Technique}

The three-phase VSI is a DC-AC power converter. The main purpose of the VSI is to provide three phase voltage source to feed the PMSM stator windings, where the amplitude and frequency of the voltages are always be controllable. The control technique used for controlling the inverter output voltage and frequency is the space vector pulse width modulation (SVPWM). It is based on the voltages in the stationary $\alpha \beta$ reference frame, which are obtained by transforming the three phase voltages by Clarke's transformation. The magnitude of the reference voltage vector can be found from the voltages in the stationary $\alpha \beta$ reference frame and used for modulating the VSI output. The result is six non-zero vectors $\left(\mathrm{V}_{1}\right.$ to $\left.V_{6}\right)$ and two zero vectors $\left(V_{0}\right.$ and $\left.V_{7}\right)$ that shaped a hexagon as shown in Fig. 1. The eight switching states of the inverter legs are shown in Table I [8].

\section{TABLE I}

The Switching Table and the Output Voltage

\begin{tabular}{|l|c|c|c|c|c|c|c|c|c|}
\hline $\begin{array}{l}\text { Volta } \\
\text { ge } \\
\text { vector } \\
\mathrm{s}\end{array}$ & \multicolumn{3}{|c|}{$\begin{array}{l}\text { Switchin } \\
\text { Vectors }\end{array}$} & \multicolumn{4}{|c|}{ phase voltages } & \multicolumn{3}{c|}{$\begin{array}{l}\text { Line } \\
\text { voltages }\end{array}$} \\
\cline { 2 - 11 } & $\mathrm{A}$ & $\mathrm{B}$ & $\mathrm{C}$ & $v_{a n}$ & $v_{b n}$ & $v_{c n}$ & $V_{a b}$ & $V_{b c}$ & $V_{c a}$ \\
\hline$v_{0}$ & 0 & 0 & 0 & 0 & 0 & 0 & 0 & 0 & 0 \\
\hline$v_{1}$ & 1 & 0 & 0 & $2 / 3$ & $-1 / 3$ & $-1 / 3$ & 1 & 0 & -1 \\
\hline$v_{2}$ & 1 & 1 & 0 & $1 / 3$ & $1 / 3$ & $-2 / 3$ & 0 & 1 & -1 \\
\hline$v_{3}$ & 0 & 1 & 0 & $-1 / 3$ & $2 / 3$ & $-1 / 3$ & -1 & 1 & 0 \\
\hline$v_{4}$ & 0 & 1 & 1 & $-2 / 3$ & $1 / 3$ & $1 / 3$ & -1 & 0 & 1 \\
\hline$v_{5}$ & 0 & 0 & 1 & $-1 / 3$ & $-1 / 3$ & $2 / 3$ & 0 & -1 & 1 \\
\hline$v_{6}$ & 1 & 0 & 1 & $1 / 3$ & $-2 / 3$ & $1 / 3$ & 1 & -1 & 0 \\
\hline$v_{7}$ & 1 & 1 & 1 & 0 & 0 & 0 & 0 & 0 & 0 \\
\hline
\end{tabular}

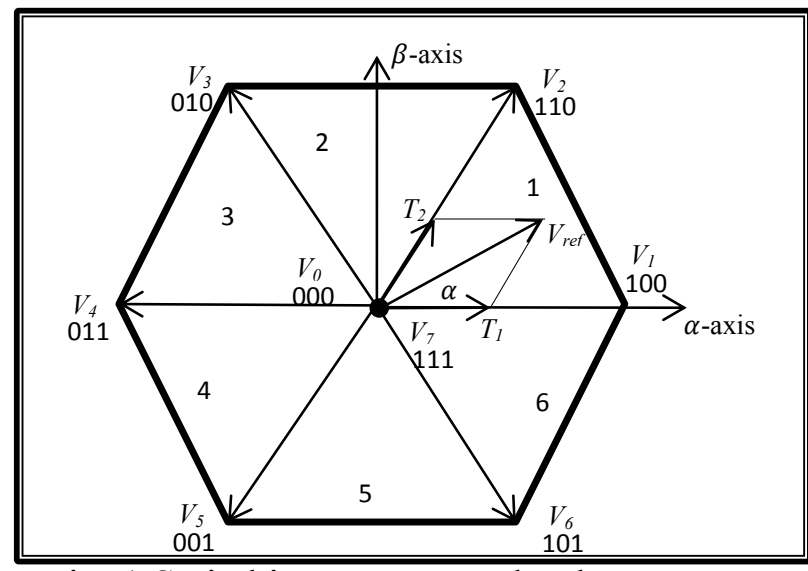

Fig. 1 Switching vectors and voltage sectors

\section{Field Oriented Control (FOC)}

Field oriented control method controls the stator current vector by transferring the threephase currents and speed of the motor to obtain a required $v_{d}$ and $v_{q}$ voltages. The three-phase 
stator currents are transferred into two phase $\alpha \beta$ system and then transfer to two phase dq system. The speed of the rotor is detected using speed sensor and is compared with the synchronous reference speed and then controlled through PI controller to produce the reference $\mathrm{i}_{\mathrm{q}}$ current, which used to control the torque of the motor. The quadrature axis current $i_{q}$ of the motor compared with the reference $i_{q}$ and another controller is used to produce the required quadrature voltage $\mathrm{v}_{\mathrm{q}}{ }^{*}$ of the voltage vector of the SVPWM inverter. The direct axis current $i_{d}$ of the motor is compared with zero and using another PI controller to produce the desired direct axis voltage $\mathrm{v}_{\mathrm{d}}{ }^{*}$ of the voltage vector. The maximum torque control is achieved by controlling $i_{q}$ with $i_{d}=0$, as shown in Fig. 2 [9].

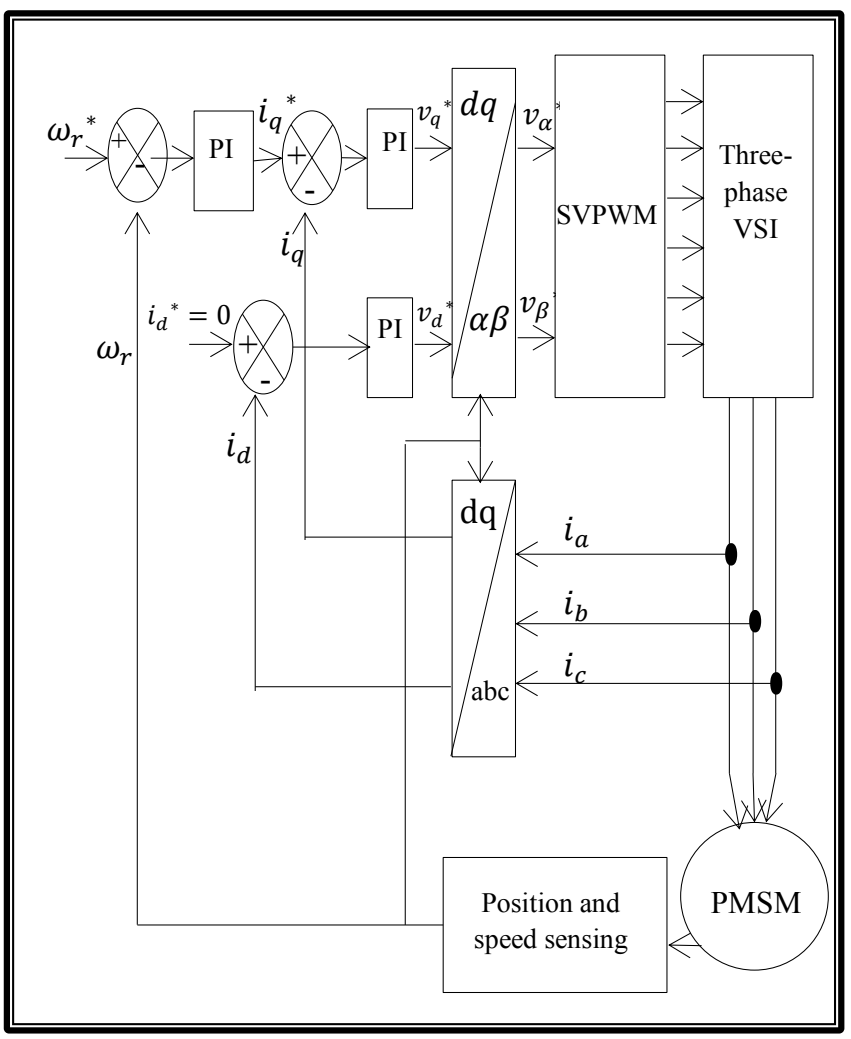

Fig. 2 FOC strategy

\section{Two PMSM-Motors Drive Structure}

There are several possible two motors drive configuration regarding coupled output torque and electric power sources. In this work the drive structure consists of two identical motors of PMSM type which are controlled independently from a two separate VSI driven by SVPWM technique as shown in Fig. 3.

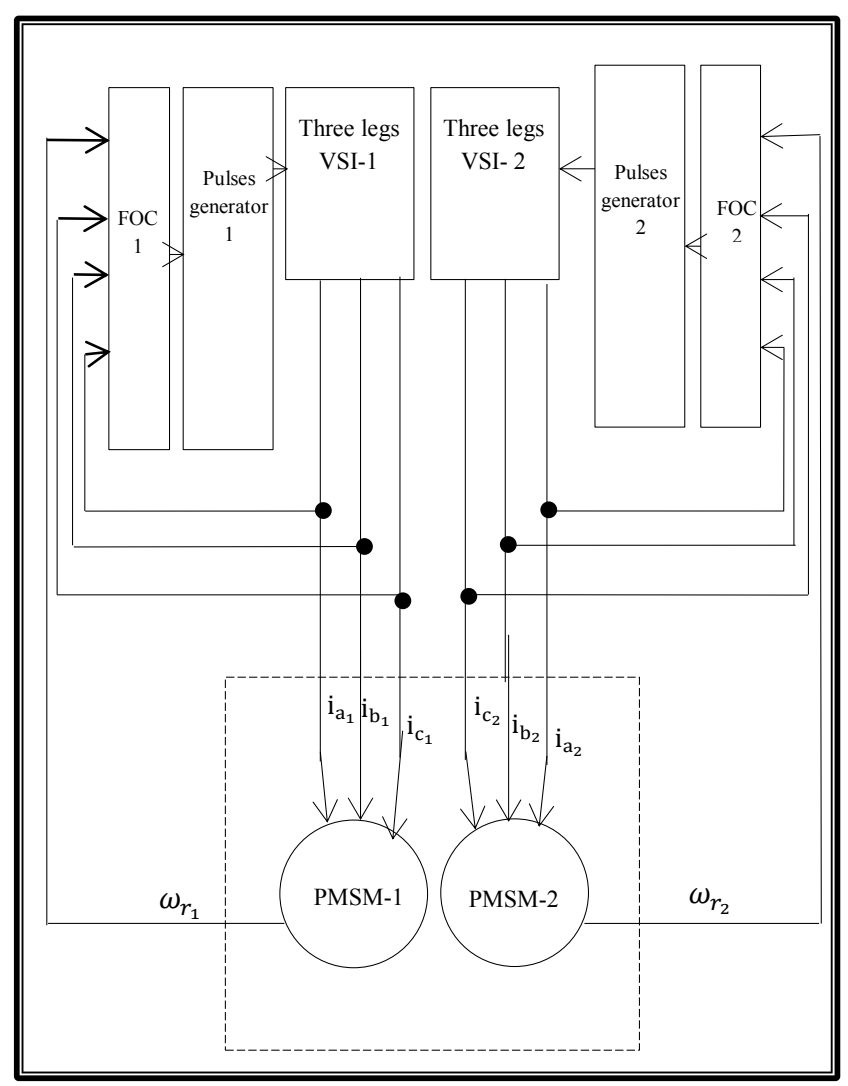

Fig. 3 Independent control of two-PMSMs

\section{Normal to Fault Tolerant Operating Proposed Strategy}

At normal operation, two identical threephase PMSMs are controlled using two identical three-phase VSI. When one leg in one of the VSI fails, the associated PMSM fails to operate, and if the two PMSMs are used for traction application then it significantly affects the traction force especially at heavy load (like in subway application). This problem can be avoided by applying fault tolerant mode, in which the two VSI are reconfigured to one five legs inverter. The reconfiguration of Fig. 3 in to five legs inverter strategy is shown in Fig. 4 [6]. The faulted leg is isolated and common leg will supply two terminals for the two motors. A nonadjacent strategy for the selection to which leg is the faulted leg connected. This strategy will prevent from the over current in the common leg and maintain this current to a value around the per fault condition. The two motors still operate independently with its FOC. A 12 to 10 pulses generator is required to drive the five legs inverter. 


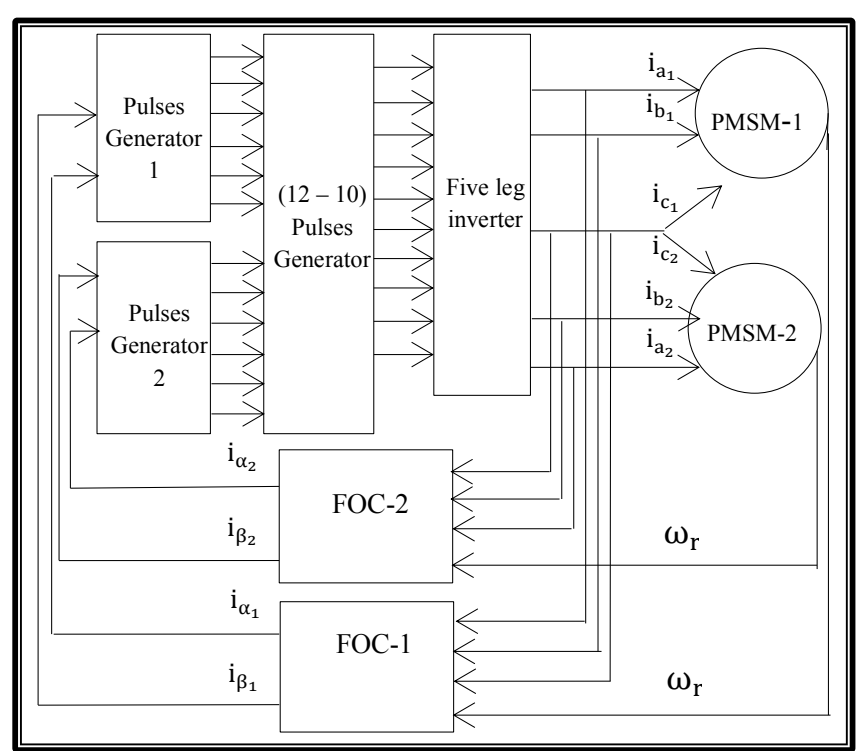

Fig. 4 Five legs inverter strategy

\section{A. Configuration of Five-Leg Inverter}

The five legs two motors drive structure contains ten switches (S1 to S10) instead of twelve switches in the standard dual three-phase VSI. Fig. 5 shows five legs inverter supplies two three-phase PMSMs; leg D is considered as a faulted leg and the non-adjacent strategy decided that leg $\mathrm{C}$ becomes the common leg. Phase $\mathrm{a}_{1}$, and $b_{1}$ of the PMSM-1 are connected to the inverter legs $A$ and $B$ respectively. Phase $\mathrm{a}_{2}$, and $\mathrm{b}_{2}$ of the PMSM-2 are connected to the inverter legs $\mathrm{F}$ and $\mathrm{E}$ respectively. Inverter $\operatorname{leg} \mathrm{C}$ is connected to $c_{1}$, and $c_{2}$ of both motors.

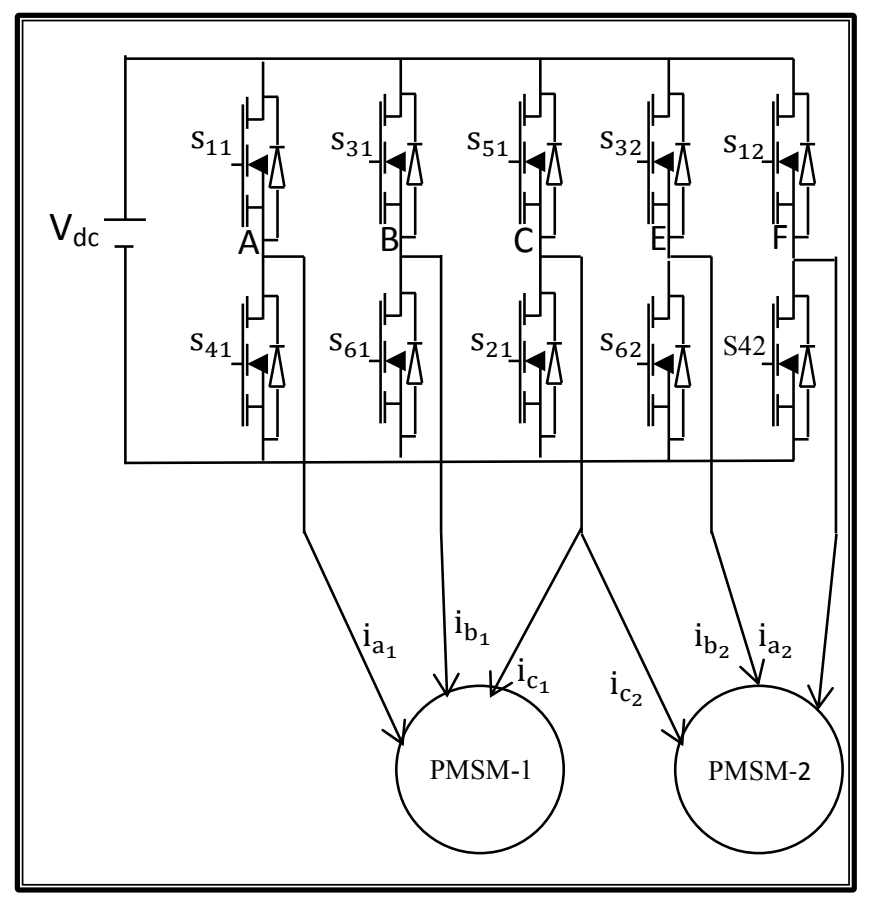

Fig. 5 Five legs inverter supplies two motors drive

\section{B. Nonadjacent Control Strategy}

The nonadjacent selection principle is used to find the optimal leg from the three legs of the healthy VSI to be connected in the common leg to protect it from the overcurrent. To satisfy the nonadjacent selection principle the phase difference between the two connected phase currents must be satisfy (5)

$$
\frac{2 \pi}{3} \leq \Delta \theta \leq \frac{4 \pi}{3}
$$

Where: $\Delta \theta=\theta_{2}-\theta_{1}, \theta_{1}$ and $\theta_{2}$ are the phase angles of the two connected phase of PMSMland PMSM-2 respectively.

The common leg in the nonadjacent selection principle is selected according to Table II to ensure that the phase difference between the two connected phase currents is according to (5) [10].

TABLE II

Common leg selection of the VSI

\begin{tabular}{|c|c|c|}
\hline $\begin{array}{c}\text { Phase difference } \\
\text { between two } \\
\text { PMSMs }\end{array}$ & Faulted leg & $\begin{array}{c}\text { Reconfiguration } \\
\text { topology }\end{array}$ \\
\hline \multirow{4}{*}[0,2\pi/3]{} & $\mathrm{A}$ & $\mathrm{AE}$ \\
\cline { 2 - 3 } & $\mathrm{B}$ & $\mathrm{BD}$ \\
\cline { 2 - 3 } & $\mathrm{C}$ & $\mathrm{CF}$ \\
\cline { 2 - 3 } & $\mathrm{D}$ & $\mathrm{DB}$ \\
\cline { 2 - 3 } & $\mathrm{E}$ & $\mathrm{EA}$ \\
\hline \multirow{5}{*}[2\pi/3,4\pi/3]{} & $\mathrm{F}$ & $\mathrm{FC}$ \\
\cline { 2 - 3 } & $\mathrm{A}$ & $\mathrm{AF}$ \\
\cline { 2 - 3 } & $\mathrm{B}$ & $\mathrm{BE}$ \\
\cline { 2 - 3 } & $\mathrm{C}$ & $\mathrm{CD}$ \\
\cline { 2 - 3 } & $\mathrm{D}$ & $\mathrm{DC}$ \\
\hline \multirow{5}{*}[4\pi/3,2\pi]{} & $\mathrm{E}$ & $\mathrm{EB}$ \\
\cline { 2 - 3 } & $\mathrm{F}$ & $\mathrm{FA}$ \\
\cline { 2 - 3 } & $\mathrm{A}$ & $\mathrm{AD}$ \\
\cline { 2 - 3 } & $\mathrm{B}$ & $\mathrm{CE}$ \\
\cline { 2 - 3 } & $\mathrm{C}$ & $\mathrm{DA}$ \\
\cline { 2 - 3 } & $\mathrm{D}$ & $\mathrm{EC}$ \\
\hline
\end{tabular}

\section{Plugging Braking Mode}

The plugging braking system is used in heavy system with very high moment of inertia and should be stopped the motor quickly like in subway train. In plugging braking, the phase sequence is reversed, and consequently result a 
reverse of driving torque, that result a consumption of energy to stop system [11].

Typically it is reverse the direction of movement of the electric motor, that result very high braking current and torque. The power is removing from the motor when it is full stop to prevent power loss and reverse rotation of motor [12]. The speed sensor is used to detect if the motor has actually stopped before removing the power. According to the high current follow in plug braking, all the electronic components and the active components should be sized and cooled accordingly.

\section{Simulink Model for the Proposed Plugging Braking}

The plugging braking is applied by reverse the phase sequence of the PMSM in order to reverse the direction of rotation, which is applied using the braking bridge. A Matlab function is used to control the switches in a braking bridge using four switching outputs $\left(\mathrm{S}_{1}, \mathrm{~S}_{2}\right)$ are used to connect or disconnect the motors and $\left(\mathrm{S}_{3}, \mathrm{~S}_{4}\right)$ to reverse the phase sequence supplied to the motors, this outputs is specified according to four inputs to the matlab function (a, b, c, d). Input (a) specify the time at which the braking is required, input (b) specify the faulted leg if existing, input (c) specify which motor (PMSM-1 or PMSM-2) is used for braking if it is required one motor, and input (d) specify if it is required both motors to braking at high speed. Another matlab functions are used in the simulated braking system to decide whether using one motor to braking or two motors depending on the speed, in which if the speed is equal or less than $0.5 \mathrm{p}$. u. the braking system use one PMSM for braking and disconnect the another one but if the speed is more than $0.5 \mathrm{p}$. u. both motors are used for braking. Fig. 6 shows the flowchart of the matlab function (brake 2) used to decide number of motors used for braking, in which a represent the speed of the motor. Fig. 7 shows the flowchart of the matlab function (brake 1) used to controlling the braking bridge. The Simulink model of the proposed plugging braking system with two three-phase PMSM operated from dual VSI and auto converted to operate from five-leg inverter in fault tolerant operation with applying FOC for each motor is shown in Fig. 8. Fig. 9 shows the simulation model of the brake bridge. Fig. 10 shows the Simulink model of the PMSM

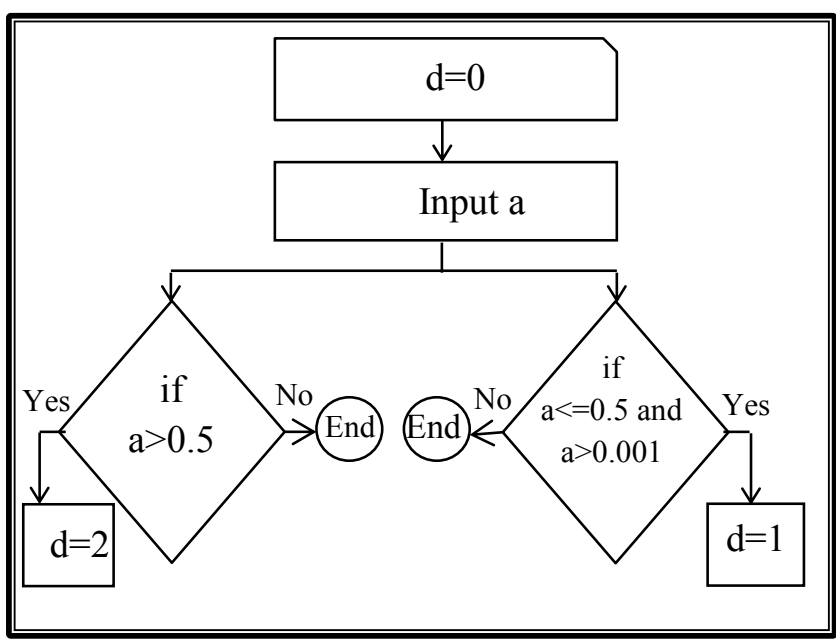

Fig. 6 Flowchart of matlab function (brake 2).

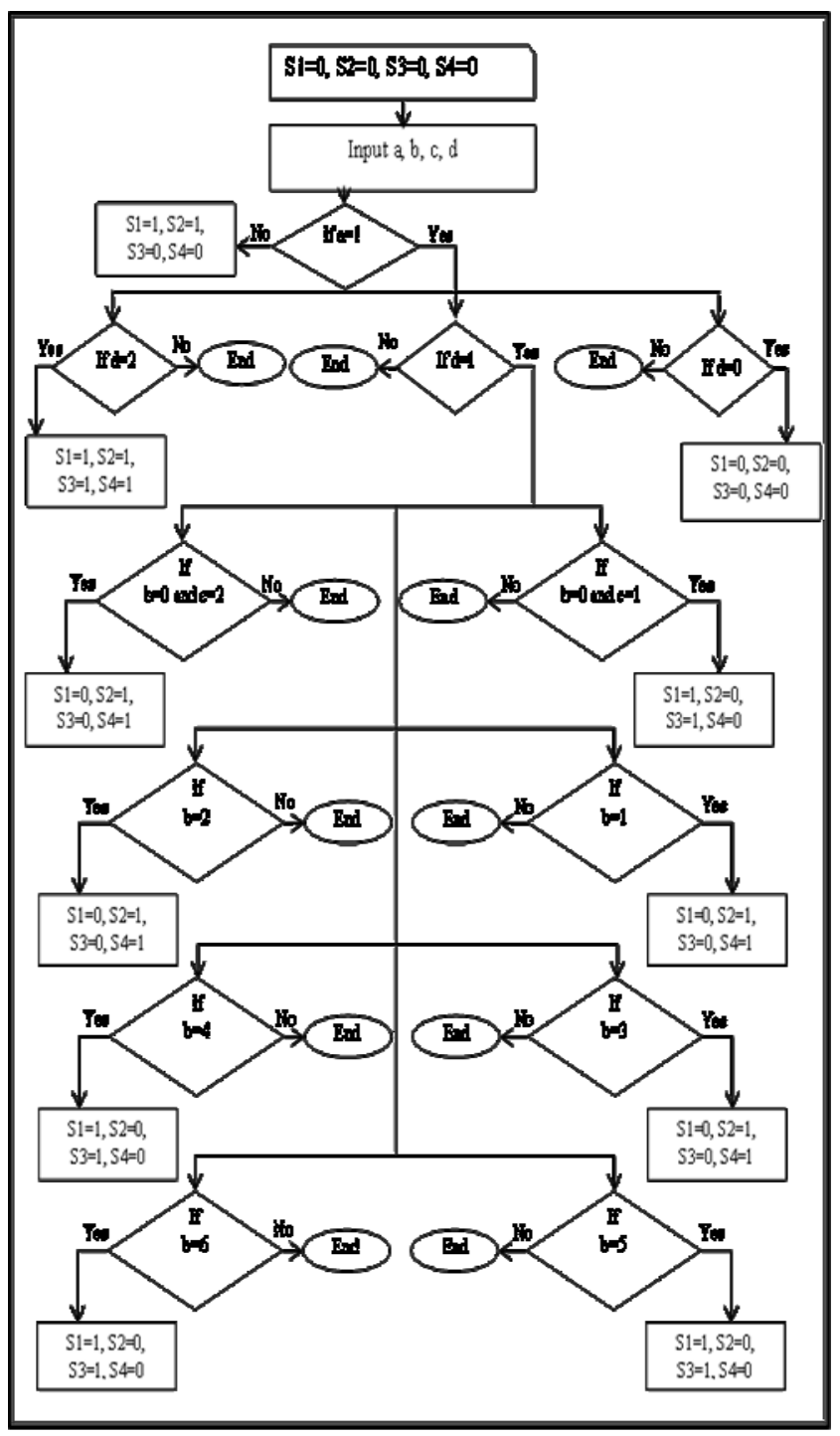

Fig. 7 Flowchart of matlab function (brake 1). 


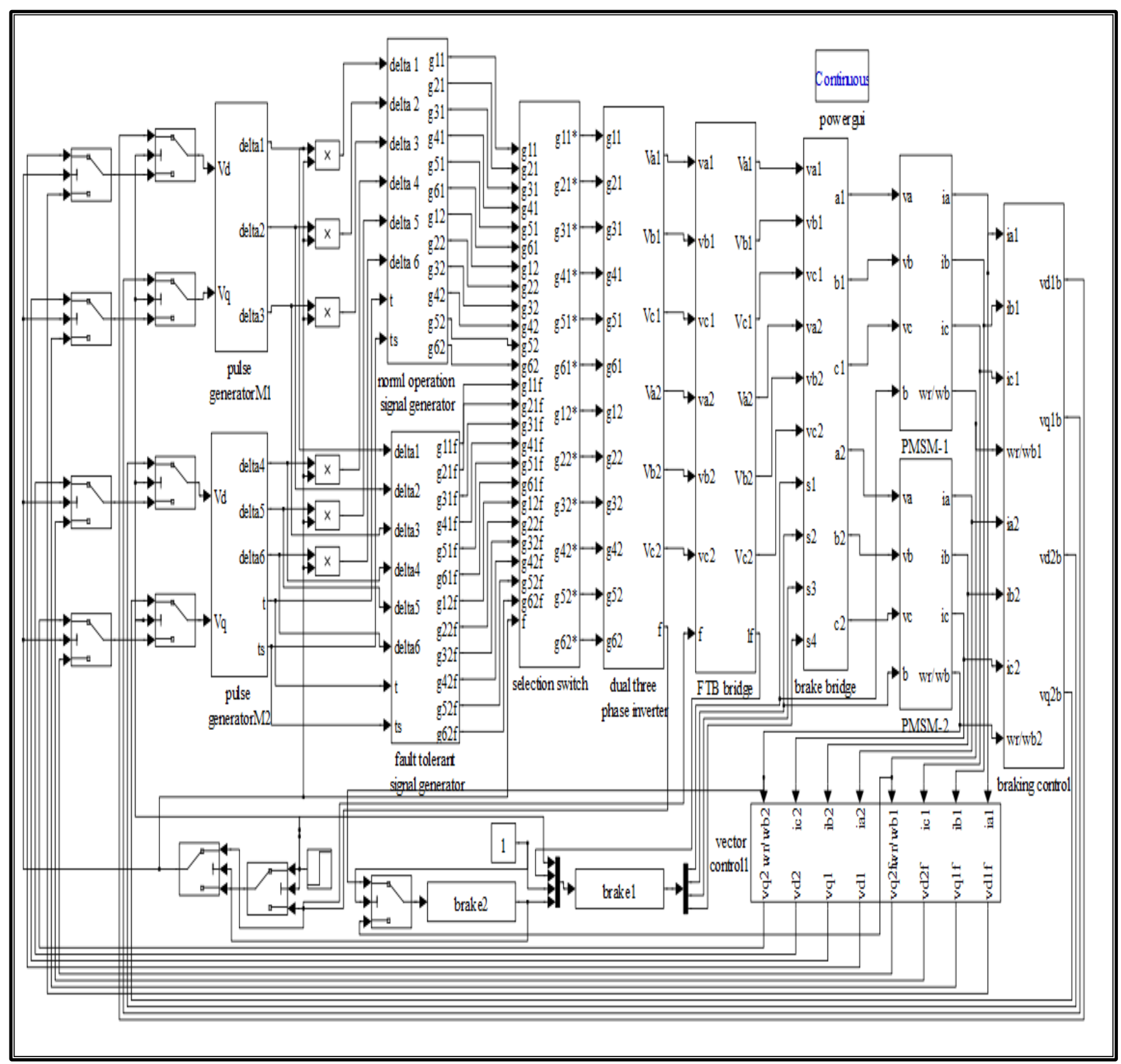

Fig. 8 Plugging braking system with normal and fault tolerant operation

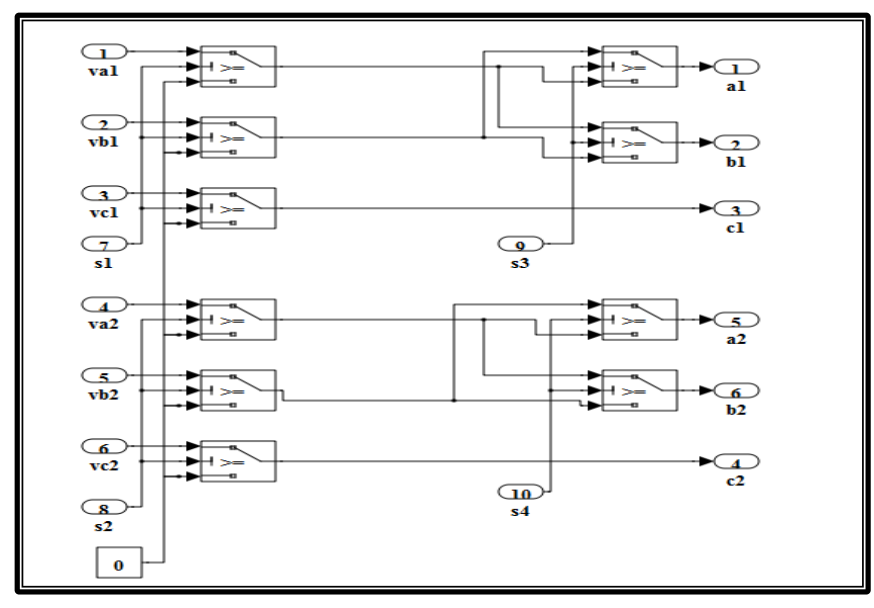

Fig. 9 Braking bridge Control

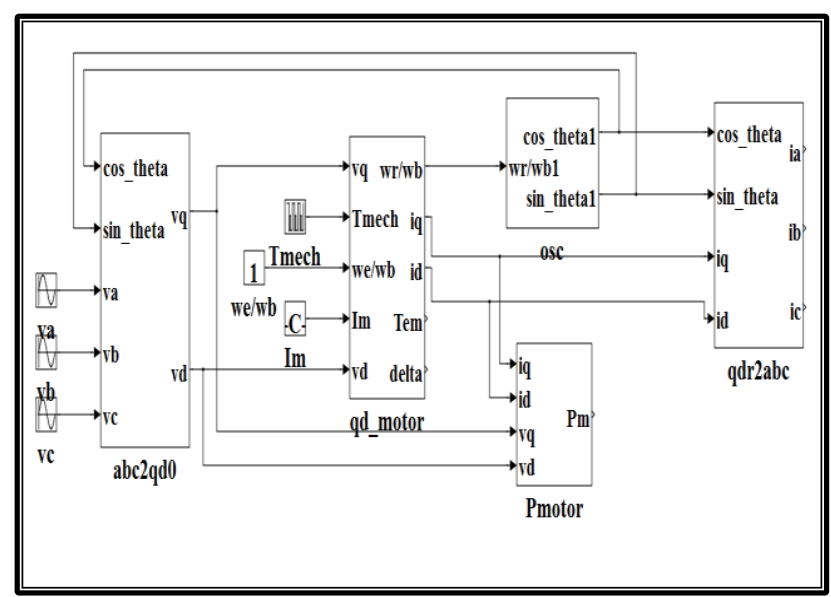

Fig. 10 Simulink model of the PMSM 
The FOC method is implemented using Clarke and Parke transformation to transfer the motor currents from the abc reference frame to $\mathrm{dq}$ reference frame, and then using three PI controllers to obtain the proper voltage in $\mathrm{dq}$ reference frame, which converted to the $\alpha \beta$ reference frame using inverse Park transformation. Fig. 11 shows the Simulink model of the FOC method.

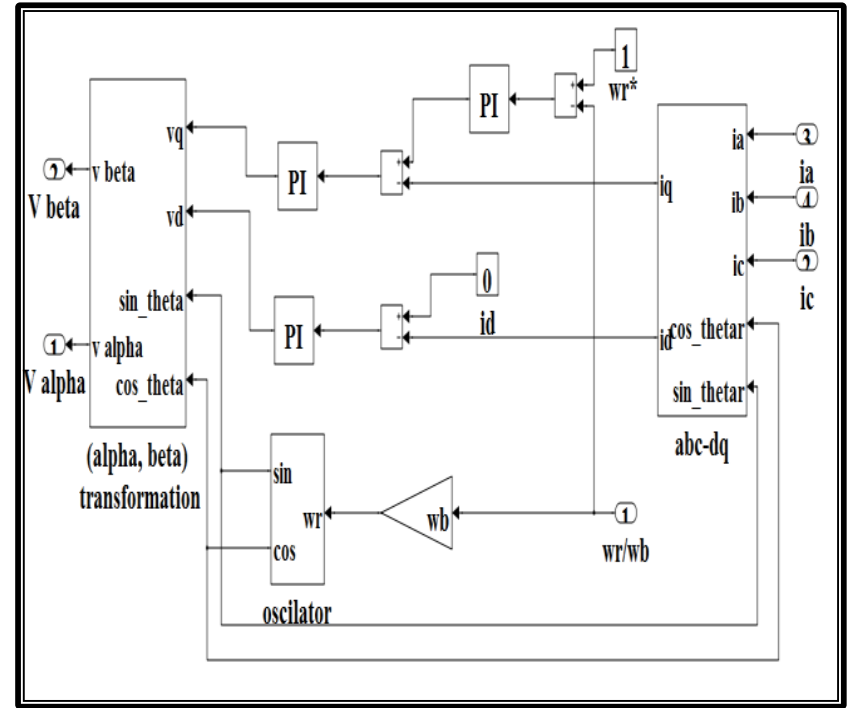

Fig. 11 Simulink model of the FOC method

\section{Simulation Results}

A series of simulations of plugging braking system have been performed using Matlab/Simulink program. The plugging braking system is applied on two $400 \mathrm{~V}, 100 \mathrm{~kW}, 60-\mathrm{Hz}$, three phase-PMSMs maximum torque and different speed operation and in normal and fault tolerant operation. The demand torque is taken at its rated value, 0.65 p.u., while the speed can be varied from 0.5 to 1 p.u. The braking time for different cases that required to bringing the motor to standstill is determined.

Fig. 12 shows the simulation results of the plugging braking system in the event of normal operation and the steady speed 0.5 p.u. The simulation results at steady speed 1 p.u. and normal mode operation are shown in Fig. 13. Fig. 14 shows the simulation results of plugging braking system at fault tolerant operation with steady speed of 0.5 p.u. Fig. 15 shows the simulation result of plugging braking system at fault tolerant mode with steady speed of 0.7 p.u.
As shown in Fig. 12 the plugging braking is applied at time $3 \mathrm{~s}$. At that time both motors at steady speed 0.5 p.u., therefor one motor is used for braking and another one is disconnected from the source and the mechanical torque. The PMSM-1 is selected for braking and PMSM-2 is disconnected. As shown from Fig. 12 a, and 12 b the speed of the PMSM-1 required $0.7 \mathrm{~s}$ to reached to zero, which is less than $2.1 \mathrm{~s}$ that required to stopping the PMSM-2. Figure $12 \mathrm{c}$, and $12 \mathrm{~d}$ shows that the current flowing through the stator windings of PMSM-1 which is increased during the plugging brake, while the current remaining flow thought the stator of the PMSM-2 until it full stop. Fig. $12 \mathrm{e}$, and $12 \mathrm{f}$ show the transient state in the electromagnetic torque during the plugging brake.

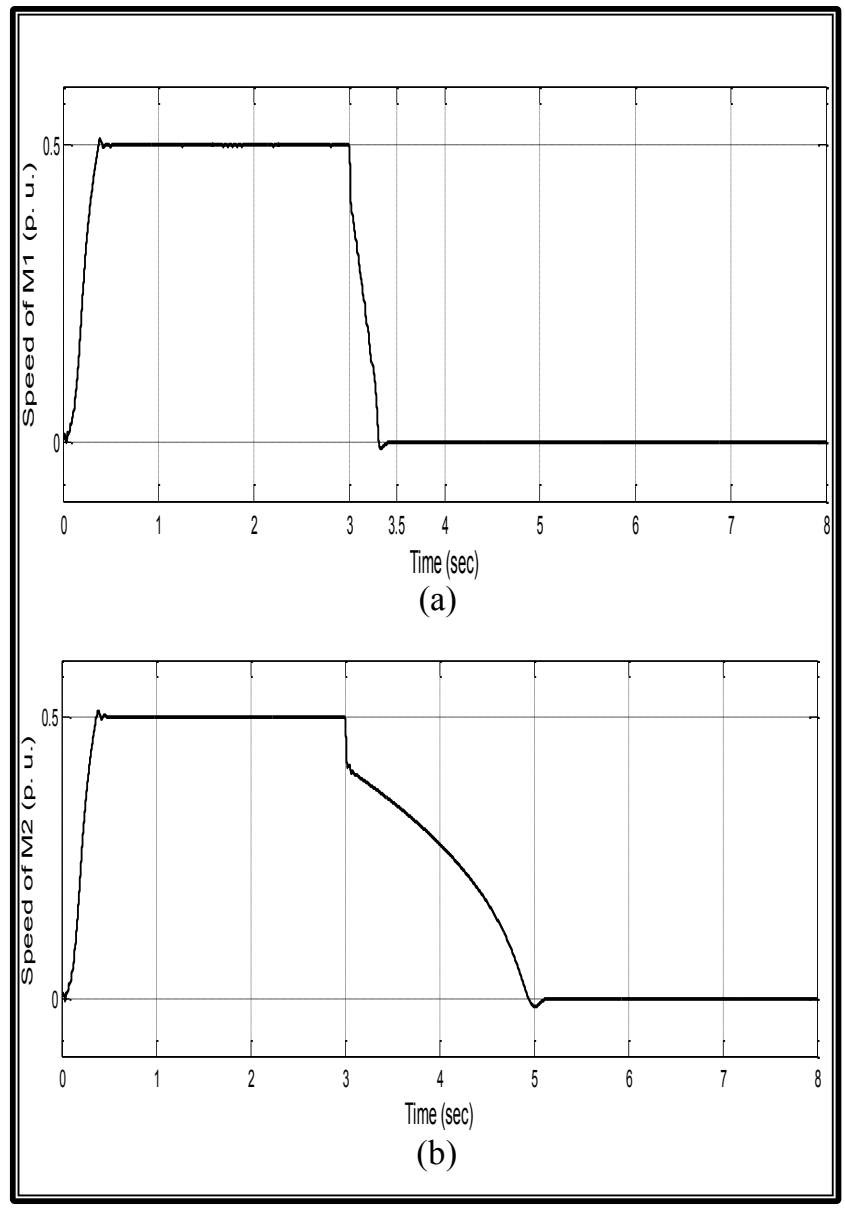

Fig. 12 Simulation result of plugging braking system at normal mode with 0.5 p.u. steady speed, (a) speed for PMSM-1, (b) speed for PMSM-2, (c) stator current for PMSM-1, (d) stator current for PMSM-2, (e) electromagnetic torque for PMSM-1, (f) electromagnetic torque for PMSM-2 


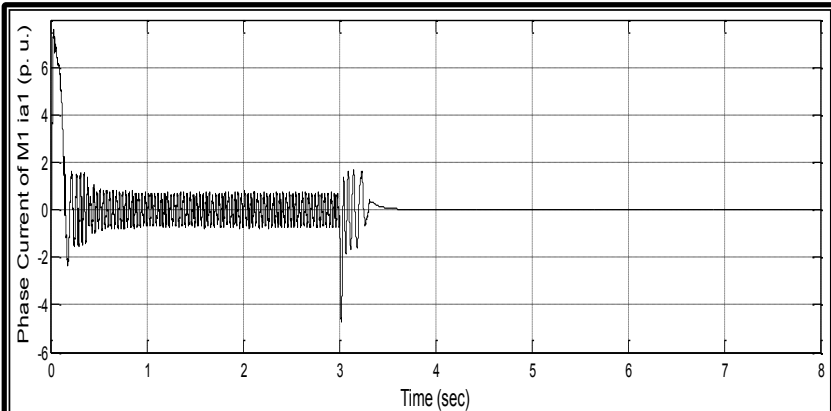

(c)

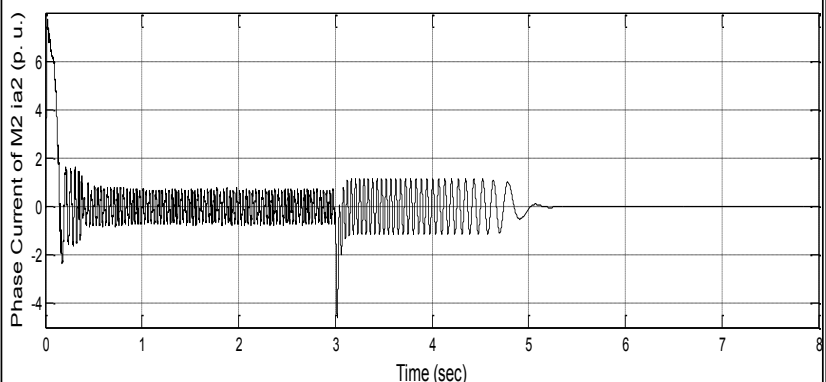

(d)

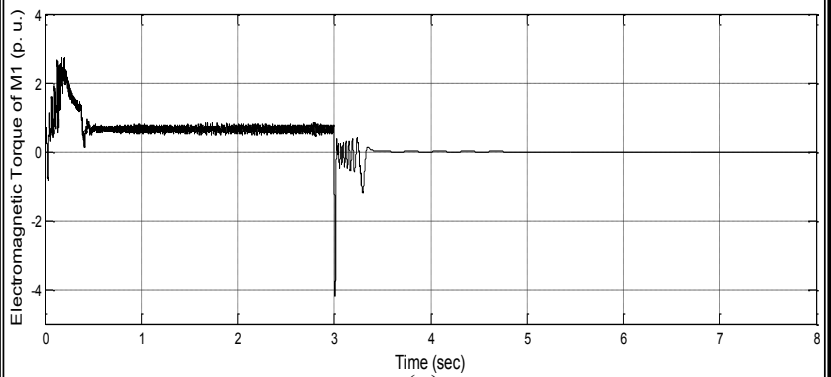

(e)

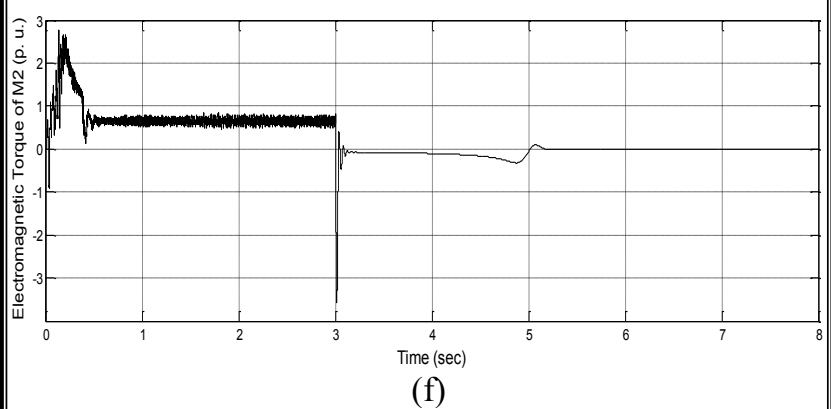

Fig. 12 continued

As shown in Fig. 13 the plugging braking is applied at time $3 \mathrm{~s}$. At that time both motors at steady speed 1 p.u., therefor both motors is used for braking to applied a high braking torque until the speed is reached to 0.5 p.u. the PMSM-1 is kept at braking and PMSM-2 is disconnected from source and the mechanical torque. As shown from Fig. 13 a the speed of the PMSM-1 required $1 \mathrm{~s}$ to reached to zero. Fig. $13 \mathrm{c}$, and 13 $\mathrm{d}$ shows that the current flowing through the stator windings of PMSM-1, PMSM-2 respectively. Fig. $13 \mathrm{e}$, and $13 \mathrm{f}$ shows the transient state in the electromagnetic torque during the plugging brake.

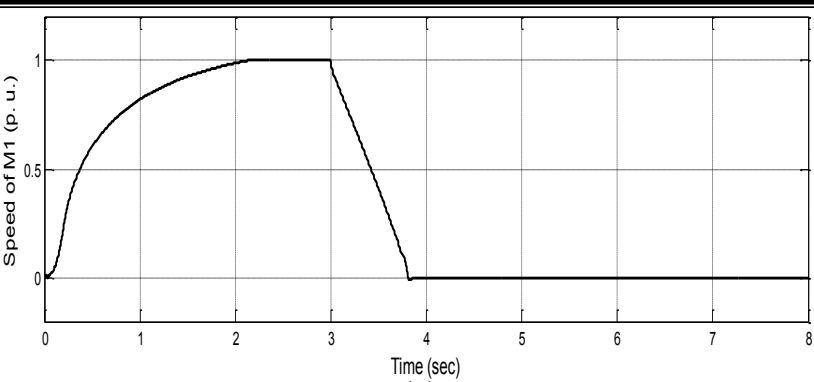

(a)

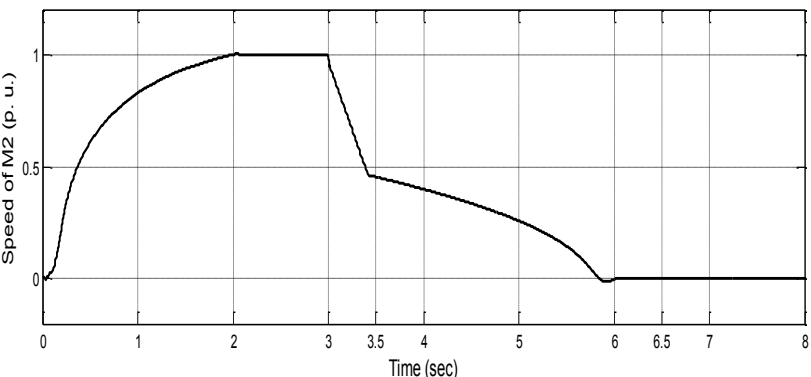

(b)

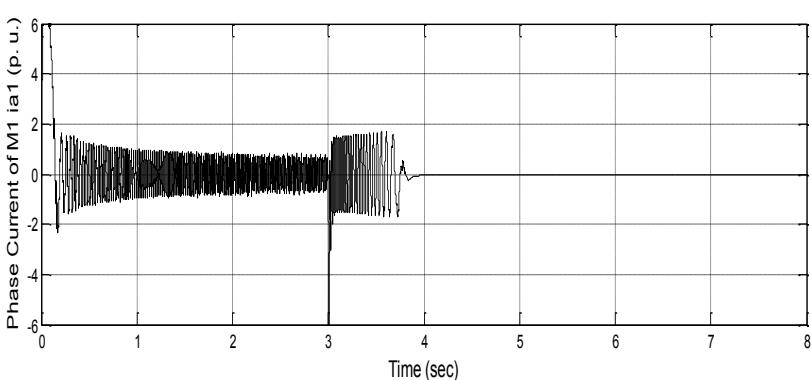

(c)

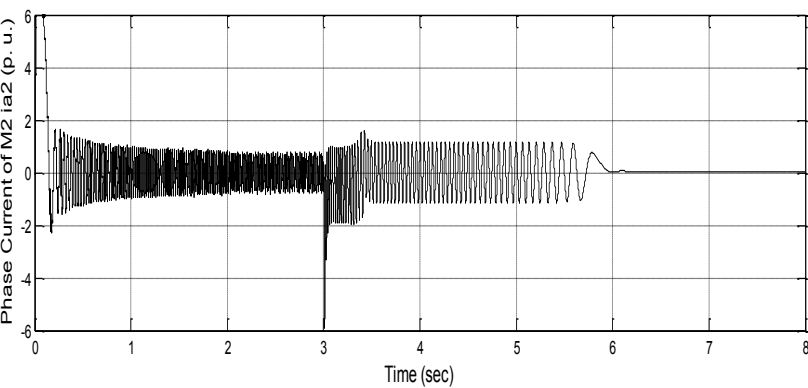

(d)

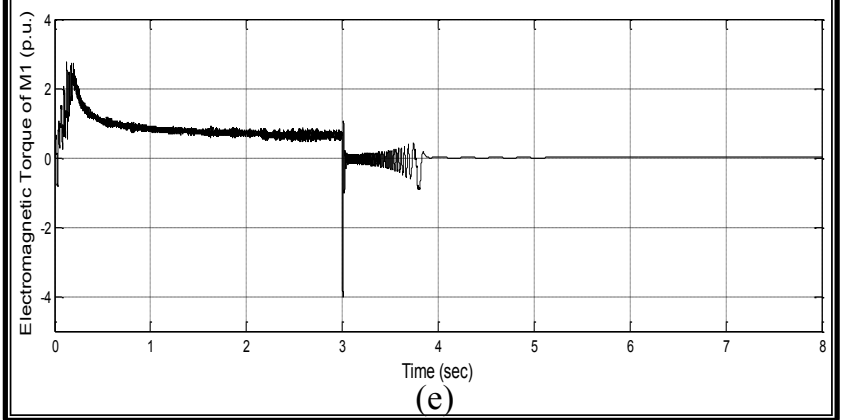

Fig. 13 Simulation result of plugging braking system at normal mode with 1 p.u. steady speed, (a) speed for PMSM-1, (b) speed for PMSM-2, (c) stator current for PMSM-1, (d) stator current for PMSM-2, (e) electromagnetic torque for PMSM-1, (f) electromagnetic torque for PMSM-2 


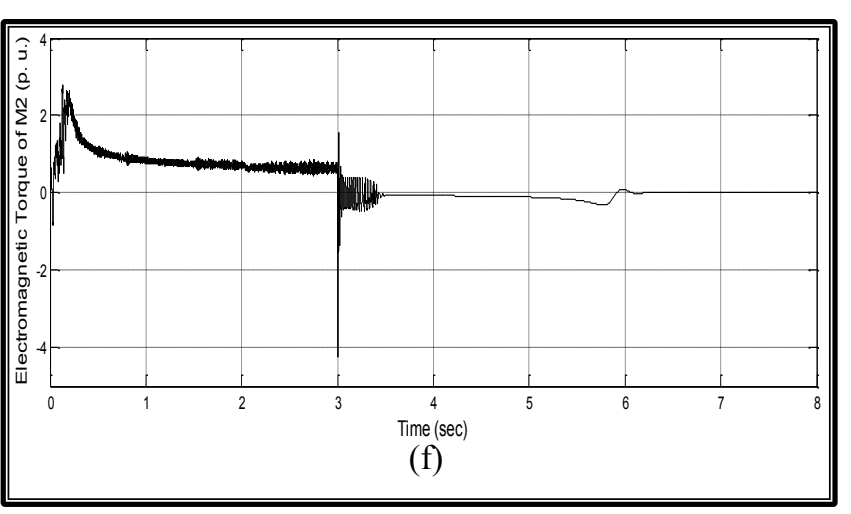

Fig. 13 continued

As shown in Fig. 14 the fault tolerant mode is applied at time $3 \mathrm{~s}$ when fault occurred at leg 4 of the dual three-phase voltage source inverter. When fault tolerant mode is applied the speed of both motors is reduced to a 0.5 p.u. and the dual three-phase inverter is reconfigured to a five legs voltage source inverter. At time $5 \mathrm{~s}$ plugging braking is applied to the system, in which the PMSM-1 is selected for braking and disconnects the PMSM-2 from the source and the mechanical torque. When the plugging brake is applied the system selects the PMSM that connected to the healthy inverter for braking and disconnect the PMSM that connected to the faulted inverter automatically. Fig. 14 a, and $14 \mathrm{~b}$ show the speed of the PMSM-1, PMSM-2 respectively. Fig. 14 c, and $14 \mathrm{~d}$ show that the current flowing through the stator windings of PMSM-1, PMSM-2 respectively. Fig. $14 \mathrm{e}$, and $14 \mathrm{f}$ show the transient state in the electromagnetic torque during the plugging brake.

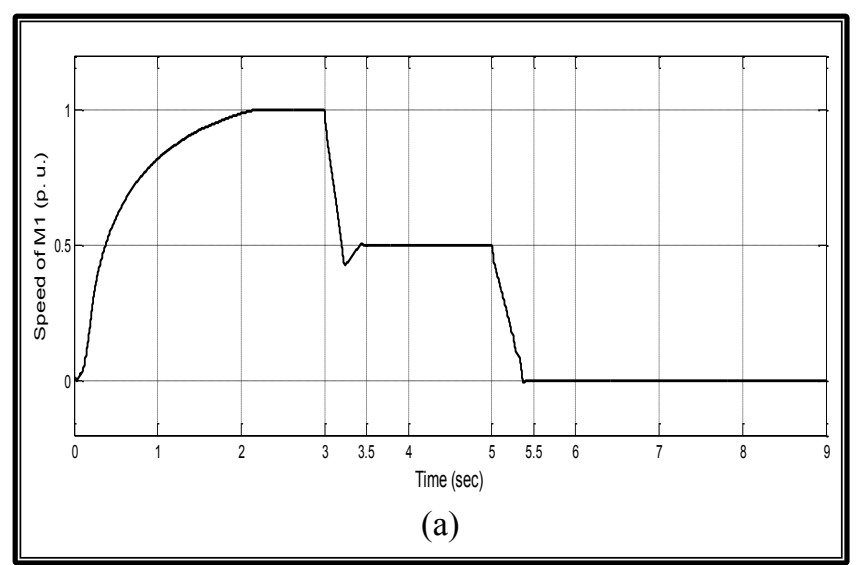

Fig. 14 Simulation result of plugging braking system with fault tolerant mode with 0.5 p.u. steady speed, (a) speed for PMSM-1, (b) speed for PMSM-2, (c) stator current for PMSM-1, (d) stator current for PMSM-2, (e) electromagnetic torque for PMSM-1, (f) electromagnetic torque for PMSM-2

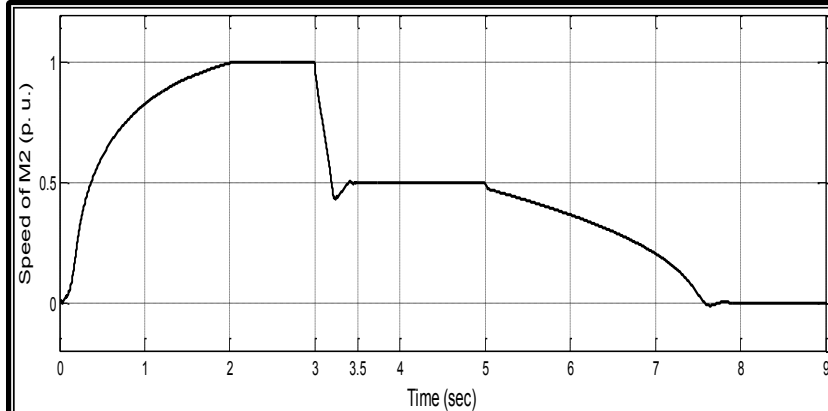

(b)

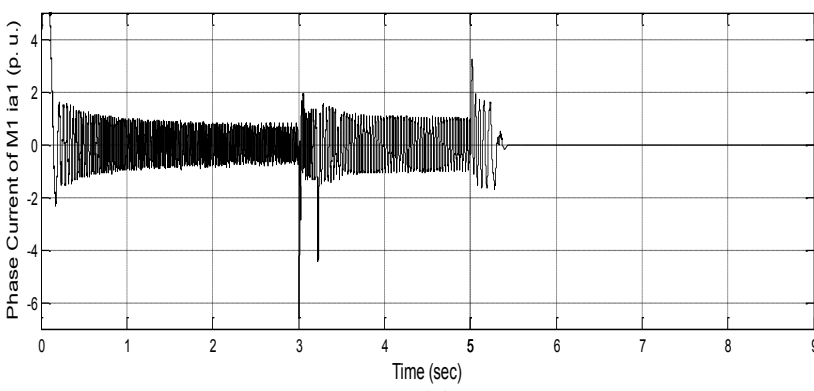

(c)

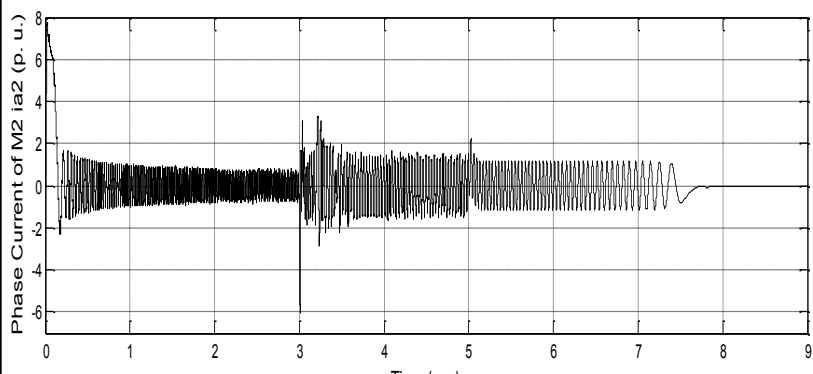

(d)

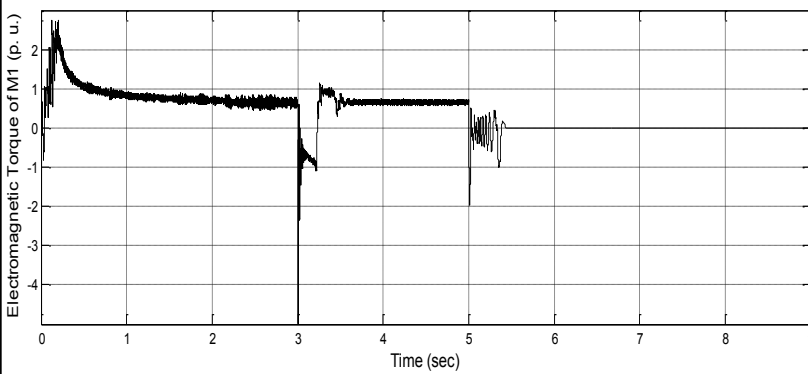

(e)

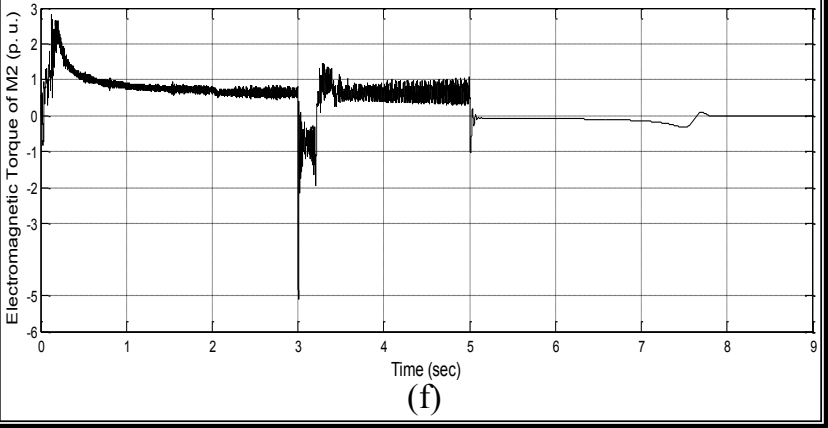

Fig. 14 continued

As shown in Fig. 15 the fault tolerant mode is applied at time $3 \mathrm{~s}$ when fault occurred at leg 4 of the dual three-phase voltage source inverter. When fault tolerant mode is applied, the speed of 
both motors is reduced to a 0.7 p.u. and the dual three-phase inverter is reconfigured to a five legs voltage source inverter. At time $5 \mathrm{~s}$ plugging braking is applied to the system. Since the speed of the motors is greater than 0.5 p.u. so the two motors are used for braking to provide a high braking torque until the speed is reached to 0.5 p.u. the PMSM-1 is kept in braking operation and the PMSM-2 is disconnected from the source and the mechanical torque. When the speed reached to a 0.5 p.u. the system selects the PMSM that connected to the healthy inverter to kept it in braking and disconnects the PMSM that connected to the faulted inverter automatically. Fig. $15 \mathrm{a}$, and $15 \mathrm{~b}$ show the speed of the PMSM1, PMSM-2 respectively. Fig. $15 \mathrm{c}$, and $15 \mathrm{~d}$ show that the current flowing through the stator windings of PMSM-1, PMSM-2 respectively. Fig. 15 e, and $15 \mathrm{f}$ show the transient state in the electromagnetic torque during the plugging brake.

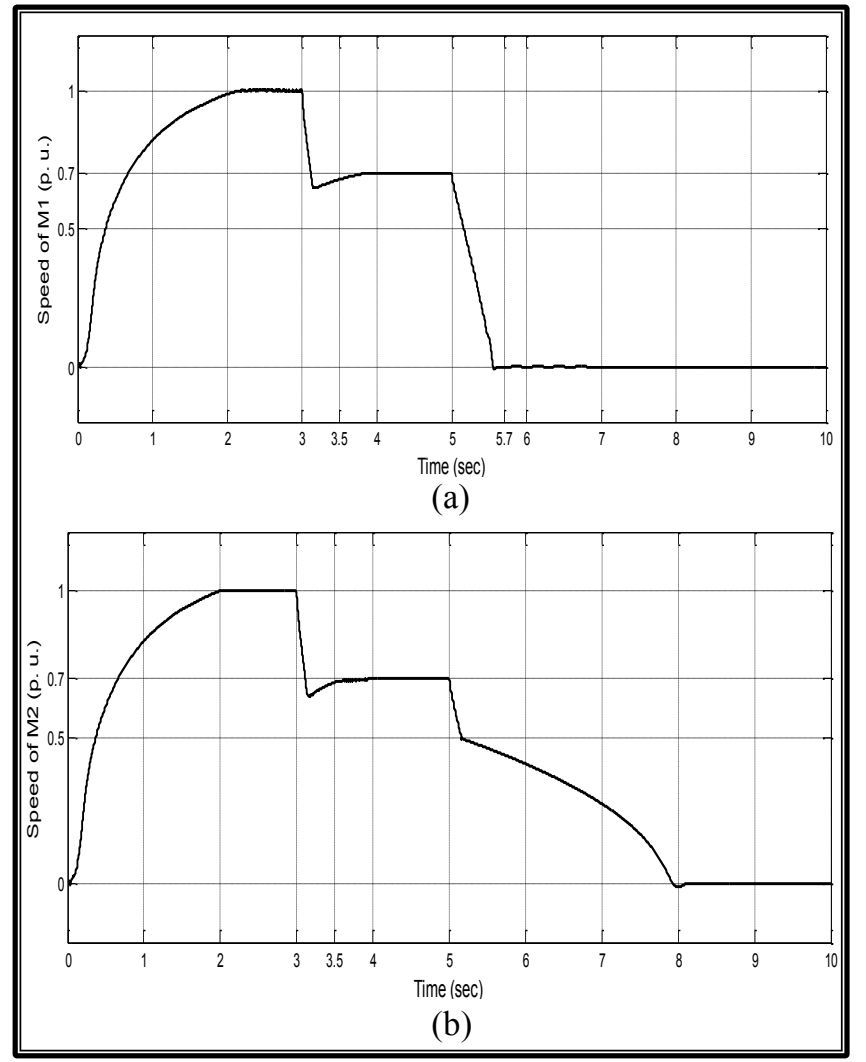

Fig. 15 Simulation result of plugging braking system with fault tolerant mode with 0.7 p.u. steady speed, (a) speed for PMSM-1, (b) speed for PMSM-2, (c) stator current for PMSM-1, (d) stator current for PMSM-2, (e) current of the common leg, (f) electromagnetic torque for PMSM-1, (g) electromagnetic torque for PMSM-2

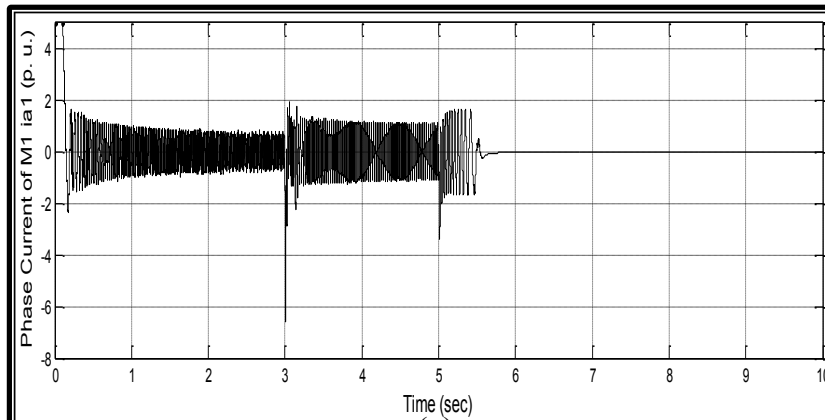

(c)

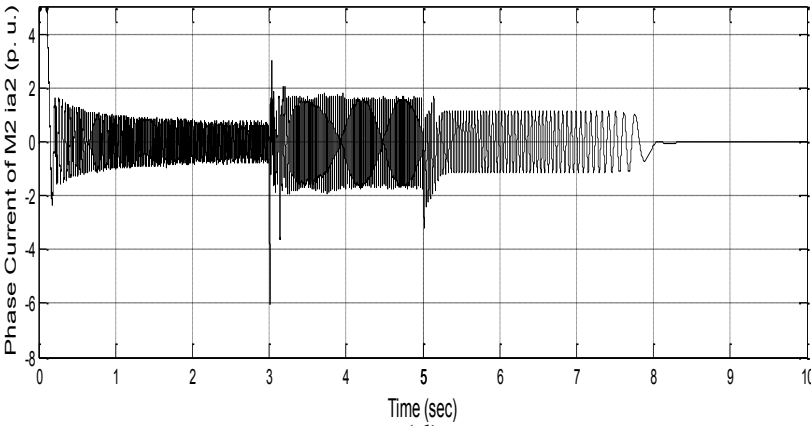

(d)

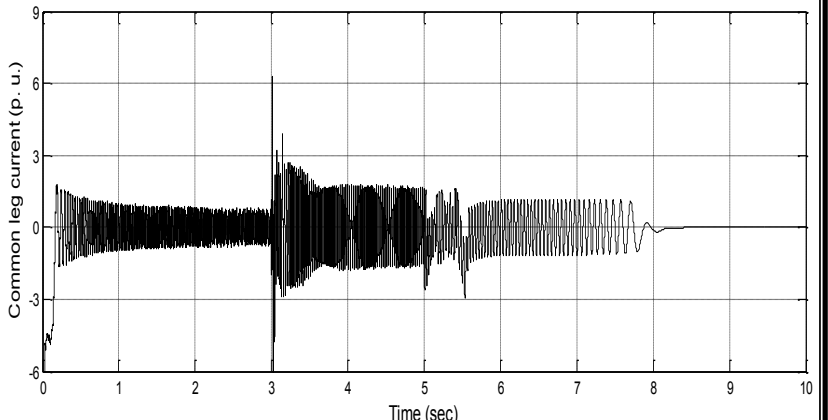

(e)

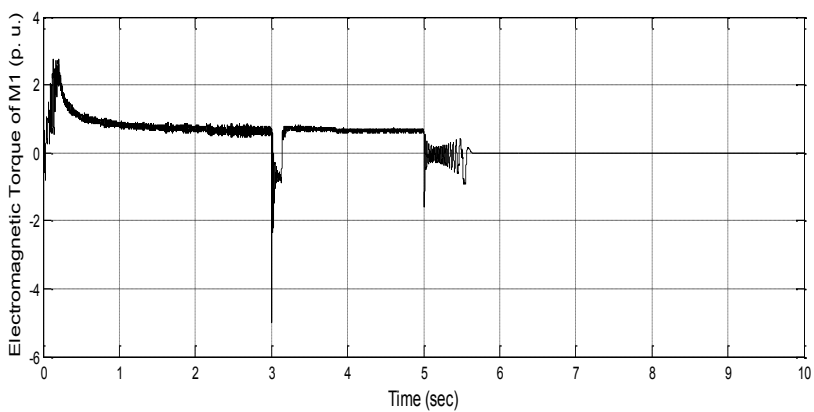

(f)

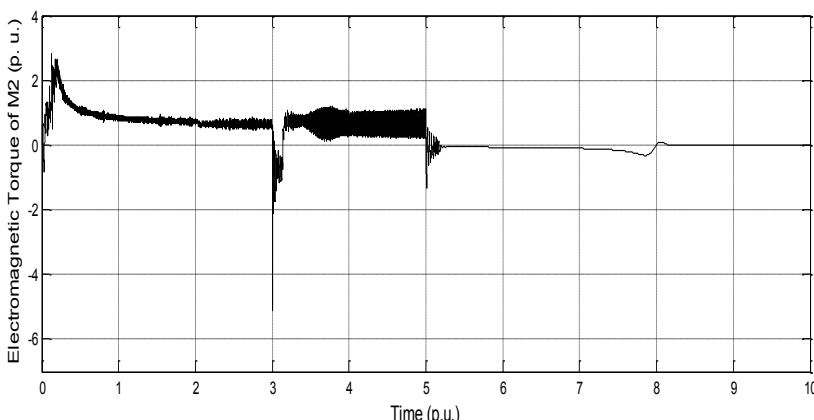

(g)

Fig. 15 continued 


\section{Conclusion}

In this paper a brief study of the plugging braking system used in the subway application is presented and Matlab/Simulink model of plugging braking system applied on two PMSMs that used as traction motors in subway train is proposed. The simulation results show that an effective and efficient plugging braking system which can be designed using PMSM and FOC method. The plugging braking is applied in normal operation of two PMSMs supplied from dual voltage source inverter with FOC using one PMSM for braking or both motor depending on the speed of the motors. When using one PMSM for plugging brake, the other one disconnect from the source and the mechanical load. Also the plugging brake is applied when the system is operated in fault tolerant mode and both motors are operated from five legs voltage source inverter. In fault tolerant operation one motor is used for braking or both motor depending on speed, also when one motor is used for braking the other one is disconnect from the source and the mechanical load. The proposed design can be used in the subway application to provide fast and safe braking.

\section{References}

[1] S. Sekalala "Preference of a Three-Phase Permanent Magnet Motor Operating as a Synchronous Motor and a Brushless DC Motor" City University of New York, August, 2006

[2] R. Dolecek, J. Novak and O. Cerny "Traction Permanent Magnet Synchronous Motor Torque Control With Flux Weakening" Radioengineering, Vol. 18, No. 4, pp. 601-605, 2009.

[3] J. Agrawal and S. Bodkhe "Sensorless Permanent Magnet Synchronous Motor Drive: A Review" National Conference on Innovative Paradigms in Engineering and Technology (NCIPET-2013), proceeding published by International Journal of Computer Applications (IJCA), pp. 1-5

[4] P.L. Rongmei, Shimi S.L, Dr. S. Chatterji and V. K. Sharma "A Novel Fast Braking System for Induction Motor" International Journal of Engineering and Innovative Technology (IJEIT),
ISSN: 2277-3754, Vol. 1, Issue 6, pp. 65-69, June 2012.

[5] C. Ong "Dynamic Simulation of Electric Machinery Using Matlab/Simulink" Purdue University, 1998, pp. 309-340

[6] M. Jones, S. N. Vukosavic, D. Dujic, E. Levi, and P. Wright, "Five-Leg Inverter PWM Technique for Reduced Switch Count TwoMotor Constant Power Applications" IET Electr. Power Appl., Vol. 2, no. 5, pp. 275-287, Sep. 2008.

[7] M. H. Talib, Z. Ibrahim, N. Abd. Rahim, and A. Sh. Abu hasim, "Implementation of Space Vector Two-Arm Modulation for Independent Motor Control Derive Fed by a Five-Leg Inverter", Journal of Power Electronics, Vol. 14, No. 1, pp. 115-124, January 2014.

[8] K. V. Kumar, P. A. Michael, J. P. John and Dr. S. S. Kumar, "Simulation and Comparison of SPWM and SVPWM Control for Three Phase Inverter", Arpn Journal of Engineering and Applied Sciences, Vol. 5, No. 7, pp. 61-74, July 2010.

[9] S. B. Inderus "The Field Oriented Control of a Permanent Magnet Synchronous Motor (PMSM) by Using Fuzzy Logic" University of Tun Hussein Onn Malaysia, pp. 8-18, 2014.

[10] W. Wang, M. Cheng, B. Zhang, Y. Zhu and S. Ding "A fault-tolerant permanent-magnet traction module for subway applications" IEEE Transections on Power Electronics, Vol. 29, No. 4, pp. 1646-1658, April 2014.

[11] Mohtar A., Nedic Z. and Machotka J. "A Compact and Affordable BLDC Motor Controller for a Microelectronics Remote Laboratory", International Conference on Embedded Systems and Applications, ESA 2008, Las Vegas, Nevada, USA, pp.75-80, 2008.

[12] Haroutuon A. Hairik, Rabee' H. Thejel, Wissam A. Kadhem "Proposed Scheme for Plugging Three-Phase Induction Motor" MELECON 2010-2010 15th IEEE Mediterranean Electrotechnical Conference, pp. 1-5, 2010. 